\title{
A Frequency Weighting for the Evaluation of Steering Wheel Rotational Vibration
}

J. Giacomin F , M.S. Shayaa, E. Dormegnie * and L. Richard ${ }^{\text {** }}$

Dept. of Mech. Engineering, The University of Sheffield, Mappin Street, Sheffield S1 3JD, UK

* Centre de Technologies Michelin Ladoux, 63040 Clermont-Ferrand Cedex 9, France

** Centre Technique Renault, Service 64261, Le Parc de Gaillon, 27940 Aubevoye, France

F Corresponding Author

Tel : 0114-222-7781

Fax : 0114-222-7890

Email : j.a.giacomin@sheffield.ac.uk 


\section{Abstract}

The human perception of rotational hand-arm vibration has been investigated by means of a test rig consisting of a rigid frame, an electrodynamic shaker unit, a rigid steering wheel, a shaft assembly, bearings and an automobile seat. Fifteen subjects were tested while seated in a driving posture. Four equal sensation tests and one annoyance threshold test were performed using sinusoidal excitation at 18 frequencies in the range from 3 to $315 \mathrm{~Hz}$. In order to guarantee the generality of the equal sensation data the four tests were defined to permit checks of the possible influence of three factors: reference signal amplitude, psychophysical test procedure and temporary threshold shift $\left(\mathrm{TTS}_{\mathrm{v}}\right)$ caused by the test exposure. All equal sens ation tests used a reference sinusoid of $63 \mathrm{~Hz}$ at either 1.0 or $1.5 \mathrm{~m} / \mathrm{s}^{2}$ r.m.s. in amplitude. The four equal sensation curves were similar in shape and suggested a decrease in human sensitivity to hand-arm rotational vibration with increasing frequency. The slopes of the equal sensation curves changed at transition points of approximately 6.3 and $63 \mathrm{~Hz}$. A frequency weighting, called Ws, was developed for the purpose of evaluating steering wheel rotational vibration. The proposed $\mathrm{W}_{\mathrm{s}}$ has a slope of $0 \mathrm{~dB}$ per octave over the frequency range from 3 to $6.3 \mathrm{~Hz}$, a slope of $-6 \mathrm{~dB}$ per octave from 6.3 to $50 \mathrm{~Hz}$, a slope of $0 \mathrm{~dB}$ per octave from 50 to $160 \mathrm{~Hz}$ and a slope of $-10 \mathrm{~dB}$ per octave from 160 to 315 Hz. $\mathrm{W}_{\mathrm{s}}$ provides a possible alternative to the existing $\mathrm{W}_{\mathrm{h}}$ frequency weighting defined in International Standards Organisation 5349-1 (2001) and British Standards Institution 6842 (1987).

Relevance to Industry: For the manufacturers of tyres, steering systems and other vehicular components the proposed $\mathrm{W}_{\mathrm{s}}$ frequency weighting provides a more accurate representation of human perception of steering wheel rotational vibration than the $\mathrm{W}_{\mathrm{h}}$ weighting of ISO 5349-1 and BS6842.

Keywords: vibration, perception, comfort, hand-arm, steering wheel, vehicles 


\section{Introduction}

Motor vehicle drivers are regularly exposed to vibrational stimuli from various sources. Of the vehicle systems which transmit vibration to the driver, the steering (Pak et al., 1991; Isomura et al., 1995) can be considered the most important due to its role in controlling the vehicle and informing the driver of the vehicle's dynamic state. The level and spectral content of steering wheel vibration depends on numerous factors including the direction of vibration, the nature of the road surface irregularities, the dynamic characteristics of the tyres and the design of the vehicle main suspension and steering mechanism. The vibrational energy transmitted to the wheel can reach frequencies of up to $300 \mathrm{~Hz}$ when driving over certain road asperities. Vibrational modes of the steering wheel and column often produce large resonances in the frequency range from 20 to $50 \mathrm{~Hz}$ (Pottinger et al., 1986). Although steering wheel vibration levels do not normally present a health risk in automobiles (Masmejean et al., 1999; Mansfield and Marshall, 2001) such vibration might nevertheless cause discomfort, annoyance and both physical and mental fatigue. Peruzzetto (1988) has shown that translational hand-arm vibration produces similar levels of perceived discomfort to translational whole-body-vibration when the acceleration level is 5 to 7 times larger. Given the acceleration levels normally measured at the steering wheel and at the seat in road vehicles, the steering vibration should be considered an important source of discomfort.

The interaction between the human hand-arm system and vibrating surfaces has been the subject of several investigations. Reynolds and Soedel (1972) studied the mechanical response of the hand-arm system to translational sinusoidal vibration in the frequency range from 20 to $500 \mathrm{~Hz}$ when gripping a handle. They concluded that arm position had only a minor effect on the impedance of the hand across the frequency range tested but that grip tightness and hand pressure influenced the vibration response at frequencies greater than $60 \mathrm{~Hz}$. They also suggested that once a method of grip had been established, the hand-arm system could be treated as a linear system. Reynolds and Angevine (1977) placed small accelerometers at eight points along the hand-arm system from the phalanx of the middle finger to the acromion of the shoulder and measured the mechanical response to handle-induced translational vibration. They showed 
that vibration at frequencies above $100 \mathrm{~Hz}$ was limited to the hand and fingers. Reynolds et. al. (1977) studied the subjective response to a vibrating handle gripped with one hand. They measured equal sensation and annoyance threshold curves for eight test subjects. The results were found to be complex in nature, but all curves showed a general tendency bwards reduced vibration sensitivity with increasing frequency.

Burström and Lundstrom (1994) assessed the influences of vibration level, direction of vibration, grip force and hand-arm posture on the absorption of translational energy by the hand-arm system. They concluded that energy absorption was dependent mainly on the frequency and direction of vibration. Absorption increased with both higher energy levels and firmer handgrips. These authors also stated that varying the hand-arm posture produced only small changes in the absorption while the size and mass of the subject's hand and arm greatly affected energy absorption. Miwa (1967) performed a series of equal sensation and annoyance threshold tests using ten subjects. Each subject performed a series of tests in which they held the palm of their hand flat against a vibrating plate, applying a pushing force which was varied over the range from 5 to $10 \mathrm{~kg}$. A paired comparison method (Gescheider, 1997) was used to establish equal sensation curves using a reference frequency of $20 \mathrm{~Hz}$ at three acceleration amplitudes of $0.31,3.1$ and $31.1 \mathrm{~m} / \mathrm{s}^{2}$ r.m.s.. After simplification the data was found to be well described by a line of constant acceleration, one of constant velocity and one of constant displacement, with transition points at 6 and $60 \mathrm{~Hz}$. The equal sensation curves were found to be in good agreement with those for whole-bodyvibration at frequencies above $10 \mathrm{~Hz}$. The curves were also found to be the same in both the horizontal and vertical directions, for one or two hands pushing against the plate and for various shapes of the handle grip.

The equal sensation curves developed for translational vibration have contributed to the definition of the $\mathrm{W}_{\mathrm{h}}$ frequency weighting which is currently used in both International Organisation for Standardization 5349-1 (2001) and British Standards Institution 6842 (1987). While being based on a simplification and an extrapolation (Griffin, 1997) of the available equal sensation data, $\mathrm{W}_{\mathrm{h}}$ was primarily defined for use in measuring and reporting hand-arm exposures for the purpose of quantifying health effects. As the only 
frequency weighting available, $\mathrm{W}_{\mathrm{h}}$ has often been used in the automotive industry for evaluating steering wheel vibrational discomfort by means of measurements performed in both the translational and rotational directions of the wheel. Some questions can be raised regarding the use of $\mathrm{W}_{\mathrm{h}}$ in the steering application, particularly its appropriateness for quantifying the tangential acceleration caused by wheel rotation.

The objective of the present study was to develop a frequency weighting (conceptually similar to $\mathrm{W}_{\mathrm{h}}$ ) for the purpose of evaluating rotational vibration in road vehicles over the frequency range from 3 to $315 \mathrm{~Hz}$. Since the equal sensation curves required to define such a weighting can be affected by numerous factors, it was decided to perform more than a single type of equal sensation test so as the check the generality and consistency of the resulting data. Four equal sensation tests were performed to check for the possible effects of three factors: reference signal amplitude, psychophysical test method and temporary threshold shift $\left(\mathrm{TTS}_{\mathrm{v}}\right)$ caused by the exposure. In addition to the equal sensation curves, an annoyance threshold test was also performed to determine the upper limit of rotational hand-arm vibration that humans are willing to accept for short periods of time.

\section{Experiment}

\subsection{Test Rig}

All tests were performed using the steering wheel rig presented in Figure 1. The rotational system consisted of a $325 \mathrm{~mm}$ diameter aluminum wheel attached to a steel shaft which was in turn mounted to two bearings. The shaft was connected to the electrodynamic shaker head by means of a copper stinger-rod. Table 1 presents the main geometric dimensions of the test rig, which were chosen based on data from a small European automobile. The seat was fully adjustable in terms of horizontal position and back-rest inclination as in the original vehicle. Rotational vibration was applied by means of a G\&W V20 electrodynamic shaker driven by PA100 amplifier (Gearing and Watson Electronics Ltd, 1995) using an external TTI TG1010 digital sine wave generator (Thurlby Thandar Instruments Ltd, 1994). The steering 
wheel tangential acceleration was measured by means of an Entran EGAS-FS-25 accelerometer attached to the top left side of the wheel. The accelerometer signal was amplified by means of an Entran MSC6 signalconditioning unit (Entran Devices Inc., 1991) and monitored using a Tektronix TDS210 oscilloscope. The test bench had a first resonance frequency of $350 \mathrm{~Hz}$. When loaded by a human hand-arm system and tested at frequencies of 4.0, 8.0, 16.0, 31.5, 63.0, 125 and $250 \mathrm{~Hz}$ at amplitudes of $0.2,2.0$ and $20.0 \mathrm{~m} / \mathrm{s}^{2}$ r.m.s. the bench provided a maximum total harmonic distortion (THD) of $15 \%$ at $4 \mathrm{~Hz}$ and $20 \mathrm{~m} / \mathrm{s}^{2}$. With both increasing frequency and decreasing amplitude the THD dropped to a minimum of $0.002 \%$ at $250 \mathrm{~Hz}$ and $0.2 \mathrm{~m} / \mathrm{s}^{2}$. During the tests which measured the bench tangential direction total harmonic distortion, a linear fore-and-aft direction acceleration measurement was also performed at the same point on the rigid wheel. Fore-and-aft acceleration was found to be no greater than $-50 \mathrm{~dB}$ with respect to the tangential acceleration in all cases measured. Test rig usage conformed to the health and safety recommendations of British Standards Institution BS7085 (1989).

\section{[Insert Figure 1 Here]}

\section{[Insert Table 1 Here]}

\subsection{Frequency Range}

The choice of test frequencies was based on the analysis of a road test database (Human Dynamics Group, 2000) which included steering wheel measurements from one European mid-sized automobile that was driven over six typical road surfaces ranging from cobblestones to smooth motorway asphalt. The road tests were performed using both 175/65 R14 and 225/45 R16 tyres at tyre inflation pressures of 1.5 and 2.0 bars respectively. Acceleration was measured in three orthogonal directions at two positions (90 and 270 degrees) along the steering wheel by means of two tri-axial accelerometers mounted on steering wheel clamps. The steering wheel power spectral densities determined from all the roads and test conditions showed that a significant amount of vibrational energy was present in the rotational direction between 10 and $60 \mathrm{~Hz}$, but that vibrational energy was much lower outside this range. Large peaks were found in the power spectral density curves between 1 and $2 \mathrm{~Hz}$ due to rigid body motion of the vehicle. For some road 
obstacles such as cleats vibrational energy was found at frequencies as high as $300 \mathrm{~Hz}$. Based on the power spectral density analysis of the road test data, 1 to $300 \mathrm{~Hz}$ appears to be the frequency range in which road vehicles present significant levels of steering wheel vibration. The maximum stroke of the test rig shaker unit $( \pm 25 \mathrm{~mm})$ limited the maximum acceleration amplitude that could be achieved at the rigid steering wheel, which in turn limited the minimum frequency that could be used for testing. For frequencies lower than approximately $3 \mathrm{~Hz}$ accurate sinusoidal acceleration signals could not be achieved at the rigid wheel. The test frequencies for the study were therefore chosen to be $1 / 3$ octave band center frequencies in the range from 3 to $315 \mathrm{~Hz}$.

\subsection{Equal Sensation Tests}

In order to guarantee the generality of the findings four different equal sensation tests were performed whose defining parameters are summarised in Table 2. These four tests made it possible to check for the possible influence of three factors on the resulting equal sensation curves: reference signal amplitude, psychophysical procedure and temporary threshold shift $\left(\mathrm{TTS}_{\mathrm{v}}\right)$ caused by the exposure. The parameter values chosen for performing these checks are discussed individually in sections 2.3.1, 2.3.2 and 2.3.3 while the remainder of the current section discusses the general methodology adopted in all cases.

Each equal sensation test was performed by means of the method of adjustment (Geschieder, 1997). A total of $181 / 3$ octave center frequencies were tested in the range from 3 to $315 \mathrm{~Hz}$ (i.e. $3,5,10,12.5,16$, $20,25,31.5,40,50,63,80,100,125,160,200,250$ and $315 \mathrm{~Hz})$. The reference stimuli for all tests was a sinusoidal vibration whose frequency value of $63 \mathrm{~Hz}$ was chosen based on the efficiency demonstrated during pretesting (Shayaa et. al. 2001) and based on the assumption that this value would help to reduce any bias that is introduced by the reference stimuli. A frequency value of $63 \mathrm{~Hz}$ is in fact in the transition region of human tactile perception thus both the non-Pacinian and the Pacinian (Verillo, 1966; Verillo 1985) mechanoreceptor systems are strongly excited and neither is favored. 
Using the method of adjustment the reference stimuli was first presented to the test subject for 10 seconds during which time the subject was asked to memorize the sensation felt in his or her hands. The steering rig excitation frequency was then changed to the test value and the subject was asked to indicate his or her perception of intensity by means of verbal cues. The subjects were required to indicate their requested adjustment to the test stimuli amplitude by stating that the test stimuli should be made "lower", "slightly lower", "higher", or "slightly higher" until the new sensation matched that of the memorized reference stimuli. By means of these verbal cues the experimenter adjusted the amplitude of the test excitation in increments of $0.04 \mathrm{~m} / \mathrm{s}^{2}$ r.m.s until an intensity similar to that of the reference stimuli was achieved. Care was taken to perform the full stimulus matching process within a 30 second time interval so as to remain within the test subject's short-term memory (Baddeley, 1997). A complete equal sensation test required approximately 15 minutes to complete the 18 test frequencies. For each test subject the order of presentation of the test stimuli was fully randomized so as to reduce fatigue and learning effects. Fatigue effects were further controlled by limiting each test subject to performing only a single equal sensation test on a given day,

\section{[Insert Table 2 Here]}

\subsubsection{Effect of Reference Stimuli Amplitude}

The shape of equal sensation curves for the hand-arm system has been shown to be a function of the amplitude of the reference signal (Griffin, 1997). To check for the possible size of this factor, equal sensation tests were performed using a $63 \mathrm{~Hz}$ fixed reference frequency at r.m.s. amplitudes of both 1.0 $\mathrm{m} / \mathrm{s}^{2}$ and $1.5 \mathrm{~m} / \mathrm{s}^{2}$. The two amplitudes were chosen to be between the threshold of vibration perception for the human skin of the hand (Morioka, 1999) and the annoyance threshold for steering wheel vibration which was established from preliminary testing (Shayaa et. al., 2001). The two tests amplitudes were also checked against the road test database and found to be representative of several driving conditions. 


\subsubsection{Effect of Temporary Threshold Shift}

Psychophysical tests such as the method of adjustment can be effected by temporary threshold shift in human perception caused by the vibration exposure. $\mathrm{TTS}_{\mathrm{v}}$ of the hand during the stimulus matching process was considered a possibly which might affect the shape of the resulting equal sensation curves. $\mathrm{TTS}_{\mathrm{v}}$ is modulated by several factors including the frequency and intensity of the vibration exposure, the duration of the exposure, the time elapsed after the exposure and the clasping, pushing and pulling forces applied to the vibrating object (Harada, 1978; Nishiyama and Watanabe, 1981). To evaluate the possibility of $\mathrm{TTS}_{\mathrm{v}}$, effects equal sensation tests were conducted using a $63 \mathrm{~Hz}, 1.0 \mathrm{~m} / \mathrm{s}^{2}$ r.m.s , fixed reference signal with and without a 30 second break after each test stimulus. For the tests which included a break the subject was required to rest their hands and to move or shake them as appropriate so as to relieve any disturbances or changes in perception that they felt. For the tests without the break the subjects were not allowed to release their hands from the steering wheel throughout the 15 minute experiment.

\subsubsection{Effect of Psychophysical Procedure}

Studies by Miwa (1967) and by Reynolds et al. (1977) have shown that equal sensation curves are affected by the choice of test procedure. To evaluate this possibility, equal sensation tests were performed using the same $63 \mathrm{~Hz}, 1.0 \mathrm{~m} / \mathrm{s}^{2}$ r.m.s, reference signal but different procedures. The first test (T3) was performed using the conventional method of adjustment involving a fixed reference stimuli as described in section 2.3. The second test (T4) was performed using a variation of the method of adjustment that involved a moving reference signal (Shayaa et al., 2001). The moving reference method has its basis in the observation that human judgment is relative rather than an absolute (Laming, 1984), thus the test result variance increases with increasing difference between the reference frequency and the test frequency. In the moving reference method the complete range of frequencies under investigation (in the case of the current study from 3 to $315 \mathrm{~Hz}$ ) is subdivided into a smaller number of ranges covering no more than one octave, or frequency doubling, within each interval. Testing begins by setting the amplitude of the center 
frequency of the center octave band, this stimuli acting as the global reference of all tests. Using this first reference stimuli testing proceeds until the equal sensation amplitudes are established for all frequencies in the center band. With the center band completed, the test frequencies bordering with the next octave intervals are assigned to act as new references and testing proceeds until all frequencies in each of the two bands have been evaluated and assigned equal sensation amplitudes. Using the equal sensation amplitudes of the test frequencies which border the neighboring bands as the reference stimuli for the neighboring bands provides a progression of tests which culminates when all frequencies in all bands have been evaluated. In the current study setting a new reference after every frequency doubling produced new reference stimuli at $16,31.5,125$ and $250 \mathrm{~Hz}$.

\subsection{Annoyance Threshold Test}

An annoyance threshold test was also performed in addition to the four equal sensation tests. The objective of the test was to establish for each frequency the maximum amplitude of rotational vibration that the test subject was willing to accept for brief periods of time. This information was considered a useful supplement to the equal sensation tests since it effectively defines the maximum vibration amplitudes for which an equal sensation, or frequency weighting, approach might result applicable. The annoyance test was performed at the same frequencies as the equal sensation tests except in the case of $3 \mathrm{~Hz}$ where the limited stroke of the shaker unit made it impossible to reach the annoyance threshold. For each test frequency the method of limits (Geschieder, 1997) was used in which the amplitude was increased in fixed increments of $0.2 \mathrm{~m} / \mathrm{s}^{2}$ r.m.s. starting from a value of $1 / 2$ of the annoyance threshold that was found in pretests (Shayaa et al., 2001). In this study the term `annoying' was explained to the subjects to mean that they would not wish to continue the exposure for more than 5 seconds. Starting from the minimum amplitude of $1 / 2$ the previously estimated threshold, the test stimuli was increased by the fixed increment every 3 to 4 seconds until the test subject indicated that he or she considered the stimulus to be annoying. A 30 second break was used in between each test frequency so as to reduce possible $\mathrm{TTS}_{\mathrm{v}}$ effects. The order of presentation of the test frequencies was fully randomized for each test subject. 


\subsection{Test Subjects and Test Protocol}

A total of 15 subjects participated in the study. A consent form and a short questionnaire was presented to each prior to testing, and information was gathered regarding their anthropometry, health, driving experience and history of previous vibration exposures. The subjects consisted mostly of university students and staff of which 10 were male and 5 were female, aged from 18 to 40 years with an mean value of 20.5 years. Height ranged from 1.5 to 2.0 meters with a mean value of 1.7 meters. Weight ranged from 45 to $90 \mathrm{~kg}$ with a mean value of $62.6 \mathrm{~kg}$. All subjects declared themselves to be in good physical and mental health. Before commencing testing, each subject was required to remove any heavy clothes such as coats, and to remove any watches or jewelry that they were wearing. They were then asked to adjust the seat position and backrest angle so as to simulate a driving posture as realistically as possible. Four postural angles were measured at the arm, wrist, back and shoulder using a full circle goniometer (Norkin, 1995). Since grip type and grip strength (Reynolds and Keith, 1977) are known to effect the transmission of vibration to the hand-arm system the subjects were asked to maintain a constant palm grip on the steering wheel using both hands. In addition, they were asked to maintain the grip strength which they felt they would use when driving on a winding country road. Mechanical coupling between the subjects and the rigid steering wheel was therefore expected to be representative of the driving task, thus involving a lower exchange of forces than is the case in applications such as hand-held power tools. The subjects were also asked to wear ear protectors and blackened (opaque) glasses to avoid any visual and auditory cues. Room temperature was maintained within the range from 20 to $25^{\circ} \mathrm{C}$ so as to avoid significant environmental effects on the skin sensitivity (ISO 13091-1, 2001). For the equal sensation tests two trial runs involving stimuli matching were performed so as to familiarize the subjects with the test procedure. For the annoyance threshold test a single example test was performed for the same reason. To avoid fatigue and learning effects, not more than a single test (equal sensation or annoyance threshold) was performed with a given subject per single day. The full test protocol was externally reviewed and found to meet the University of Sheffield guidelines for good research practice. 


\section{Results}

\subsection{Effects of Test Stimuli Frequency and Amplitude}

Table 3 presents the mean and one standard deviation values obtained for each frequency for each equal sensation test. For each frequency the mean values can be seen to be similar between testes 1,3 and 4 which all used the $1.0 \mathrm{~m} / \mathrm{s}^{2}$ reference stimuli. Also of interest is that, as expected from psychophysical theory (Geschieder, 1997), the mean equal sensation amplitudes matched to the reference frequency of 63 $\mathrm{Hz}$ did not provide the original 1.0 or $1.5 \mathrm{~m} / \mathrm{s}^{2}$ values of the stimuli. The amplitudes were found to be from 3 to 10 percent higher. Another feature that can be observed from the data is that the standard deviation was found to generally increase with increasing test frequency, indicating a greater difficulty on the part of the test subjects to distinguish high frequency stimuli.

Figure 2 presents the four mean equal sensation curves (2a, 2b, 2c and 2d) and the annoyance threshold curve (2e) determined in the current study in terms of r.m.s acceleration amplitude versus frequency. A high degree of similarity in shape can be noticed between the curves, particularly between the four equal sensation curves. The equal sensation curves suggest an approximately constant acceleration dependency from 3 to $5 \mathrm{~Hz}$. For frequencies greater that $5 \mathrm{~Hz}$ the equal sensation curves increase approximately monotonically until $40 \mathrm{~Hz}$. In the frequency interval from 40 to $80 \mathrm{~Hz}$ the curves exhibit again a trend of approximately constant acceleration dependency. Above $60 \mathrm{~Hz}$ the equal sensation curves can be described as following a non-linear dependency on frequency up to the maximum test result obtained at $315 \mathrm{~Hz}$.

\section{[Insert Table 3 Here] [Insert Figure 2 Here]}

From Figure 2 it can be observed that the equal sensation curves obtained using the reference stimuli of 1.0 and $1.5 \mathrm{~m} / \mathrm{s}^{2}$ (Test 1 and Test 2) are separated in amplitude but have similar shape. To investigate the 
similarity in shape of the curves, and thus the similarity in frequency dependency, the data of test 2 was normalized to the reference amplitude of test 1 (i.e $1.0 \mathrm{~m} / \mathrm{s}^{2}$ r.m.s). For each of the 18 frequencies a one factor repeated measures ANOVA (Hinton, 1998) was performed at a 5 percent confidence level by taking the equal sensation test to which the data belonged (Test 1 or normalized Test 2 ) to be the test condition. In all 18 ANOVA tests the differences between the data sets were found to not be significant a 5 percent level, thus confirming the similarity in shape. While amplitude dependency has occasionally been identified described in literature in cases involving translating handles, the current study suggests that any such changes are relatively small in the case of rotational accelerations at amplitudes encountered in road vehicles.

\subsection{Effects of TTS $_{V}$ and of Psychophysical Procedure}

Comparison of the data of Table 3 for equal sensation test 1, involving a 30 second break between stimuli, and equal sensation test 3 , involving no break between stimuli, suggests that $\mathrm{TTS}_{\mathrm{v}}$ did not have a large effect on the equal sensation data. As in the case of reference stimuli amplitude, a check was performed of the differences between the two data sets (T1 and T3). For each of the 18 frequencies a one factor repeated measures ANOVA was performed at a 5 percent confidence level by taking the equal sensation test to which the data belonged ( $\mathrm{T} 1$ or $\mathrm{T} 3$ ) to be the test condition. In all 18 ANOVA tests the differences between sets $\mathrm{T} 1$ and $\mathrm{T} 3$ were found to not be significant a 5 percent level, thus confirming the limited effect of introducing a 30 second recovery period between stimuli. The mean value curves of Figure $2 \mathrm{a}$ and $2 \mathrm{c}$ confirm the similarity of the equal sensation curves obtained with and without the break.

Use of the moving reference frequency test procedure was found to lead to greater differences in the test results than the other factors investigated. In order to determine the fequencies at which the greatest differences occurred a one factor repeated measures ANOVA was performed between sets T3 and T4 for each of the 18 test frequencies at a 5 percent confidence level. In this case statistically significant differences were found at all test frequencies below $20 \mathrm{~Hz}$, i.e. 3, 5, 10, 12.5 and $16 \mathrm{~Hz}$. Further proof of 
the difficulties with the moving reference method can be noted in the standard deviation values of Table 3 where the moving reference procedure of $\mathrm{T} 4$ presents standard deviation values up to 50 percent greater than with the traditional method of adjustment (T3).

\section{Frequency Weighting Curve $W_{s}$}

Using the data from equal sensation tests 1 and 2, a frequency weighting for evaluating hand-arm discomfort due to rotational steering wheel vibration was developed. Use of these data sets appears to be appropriate in this study due to their intermediate position above mean skin perception threshold curves and below the annoyance threshold As a first step towards determining a frequency weighting the data of the two equal sensation curves was normalized to the same reference stimuli intensity of $1.0 \mathrm{~m} / \mathrm{s}^{2}$. Regression curves were then constructed through the equal sensation data points over three segments; from 3 to $6.3 \mathrm{~Hz}$, from 6.3 to $50 \mathrm{~Hz}$ and from 50 to $315 \mathrm{~Hz}$. For the first two segments linear regression was performed of the form

$$
s=b f+a
$$

where $s$ is the acceleration value in $\mathrm{m} / \mathrm{s}^{2}$ r.m.s., $b$ is the slope of the curve, $f$ is the frequency in units of $\mathrm{Hz}$ and $a$ is the yaxis intercept. From 50 to $315 \mathrm{~Hz}$ a quadratic expression was fitted through the data points using a $2^{\text {nd }}$ order polynomial

$$
s=c f^{2}+b f+a
$$

where $\mathrm{c}$ is the coefficient of the quadratic term. The regression results including the coefficients of determination are presented in Table 4. The mean coefficient of determination $\left(\mathrm{R}^{2}=0.94\right)$ across the frequency range suggested an acceptable fit. The regression lines (shown in Figure 3a) were then inverted 
and normalized to a maximum value of unity (shown in Figure 3b) thus serving as the basis from which to define the frequency weighting.

The frequency weighting was given the name $\mathrm{W}_{\mathrm{s}}$ due to its intended use in evaluating steering vibration. $\mathrm{W}_{\mathrm{s}}$ is defined to have a slope of $0 \mathrm{~dB}$ per octave over the frequency interval from 3 to $6.3 \mathrm{~Hz}$ based on the simplification of the current results (since the slope over this interval was small) and based on Miwa's (1967) equal sensation data. In the frequency interval from 6.3 to $50 \mathrm{~Hz}$ the slope of $\mathrm{W}_{\mathrm{s}}$ is defined to be $6.0 \mathrm{~dB}$ per octave. In the interval from 50 to $160 \mathrm{~Hz}$ Ws is defined to have a slope of $0 \mathrm{~dB}$ per octave (a line of constant acceleration) based on a simplification of the regression curves in this transition region. Finally, in the interval from 160 to $315 \mathrm{~Hz} \mathrm{~W}_{\mathrm{s}}$ was taken to have a linear characteristic of slope of $-10 \mathrm{~dB}$ per octave since the quadratic dependency was relatively small. In absence of evidence to the contrary, the authors suggest that vibrational energy below $3 \mathrm{~Hz}$ should not be evaluated and that, in accordance with principles established by the ISO 5349-1 (2001) guidelines, vibrational energy above $315 \mathrm{~Hz}$ be treated by extending the asymptotic line of the frequency weighting up to $2000 \mathrm{~Hz}$.

\section{[Insert Table 4 Here] [Insert Figure 3 Here]}

\section{Discussion}

The four equal sensation curves obtained in this study were found to be similar in terms of shape. Of the factors which were thought to possibly effect the equal sensation tests, the psychophysical test procedure was found to have the largest effect. The moving reference test procedure produced a larger data variance than the use of the more traditional method of adjustment based on a fixed reference stimuli. Statistically significant differences $(\mathrm{p}>0.05)$ in the equal sensation amplitude values were found between the two data sets at all test frequencies below $20 \mathrm{~Hz}$ for group of test subjects $(\mathrm{n}=15)$. Below $20 \mathrm{~Hz}$ the moving reference method produced higher mean acceleration amplitudes. The other two factors investigated, the use of breaks between test stimuli to minimize $\mathrm{TTS}_{\mathrm{v}}$ and a change of reference stimuli amplitude from 1.0 
to $1.5 \mathrm{~m} / \mathrm{s}^{2}$, did not produce statistically significant differences $(\mathrm{p}>0.05)$ in the equal sensation results on a frequency by frequency basis. In both cases the findings can possibly be explained by the short duration of the reference signals and the relatively low vibration intensities involved.

The equal sensation data determined in the current study can be compared to the data obtained by Miwa (1967) for the human hand-arm system pressed against a translating plate and to the data obtained by Reynolds et. al. (1977) from measurements performed with a translating handle. Figure 4a presents a combined plot of the Miwa data for the vertical direction, the Reynolds et. al. data for the axial direction and the $1.0 \mathrm{~m} / \mathrm{s}^{2}$ equal sensation data of test 1 from the current study. As shown in Figure 4a the data from all three studies suggest a similar trend of reduced sensitivity of vibration perception with increasing frequency. The reduction in sensitivity was greater in Miwa's data than in either that of Reynolds et al. or the current results. Miwa's curves were similar across different hand-arm postures and along different vibration directions, thus a possible explanation for the differences with respect to the other two data sets may be the use of the method of paired comparisons as opposed to the method of adjustment. A more probable explanation is, however, the choice of a relatively low $20 \mathrm{~Hz}$ reference frequency. In pretesting performed prior to the current study (Shayaa et al., 2001) the authors obtained a similar apparent reduction in sensitivity at high frequencies when using a $10 \mathrm{~Hz}$ reference as opposed to the $63 \mathrm{~Hz}$ reference of the current study. Figure $4 \mathrm{~b}$ presents a summary of the three data sets obtained by choosing the lowest acceleration amplitude value found at each test frequency. The synthesis result suggests changes in the nature of the human perception of vibration at two transition points: $6.3 \mathrm{~Hz}$ and $80 \mathrm{~Hz}$. Three regression curves were used to model the behavior of the synthesis curve over the interval from 1 to $1000 \mathrm{~Hz}$. The segments from 1.0 to $6.3 \mathrm{~Hz}$ and from 6.3 to $80 \mathrm{~Hz}$ were found to be best modeled by a linear expression while a quadratic expression was found to be required for the third segment from 80 to $1000 \mathrm{~Hz}$. The regression equations and the coefficients of determination for each segment are presented in Table 5. Below $6.3 \mathrm{~Hz}$ the regression line of the synthesis curve can be simplified to a line of constant acceleration as in the work of Miwa. 
Some observations can be made regarding the transition points of the data synthesis curve obtained by considering also previous research. The known frequency response characteristics (Verillo, 1966; Verillo, 1985; Bolanowski et al., 1988) of the human skin mechanoreceptors suggest that it is unlikely that changes in their output causes the transition point at approximately $6.3 \mathrm{~Hz}$. Verbal commentary obtained from the test subjects during the current study suggests instead that the transition is caused by the onset of mechanical decoupling of the upper arm and shoulder from the vibration source at the wheel. In the region from 5 to $10 \mathrm{~Hz}$ a visible decoupling occurs in which the response amplitude drops noticeably in the upper arm and upper body regions. Direct support for this hypothesis can be found in the results of Reynolds and Angevine (1977) where acceleration transmissibilities were found to drop sharply above $10 \mathrm{~Hz}$. Indirect support can be found in the research by Giacomin (2000) which used a body part discomfort form to evaluate the subjective sensation of discomfort caused to upper body regions by rotational steering wheel vibration of fixed frequency. The known frequency response characteristics of the human skin mechanoreceptors suggest that the transition in the region from 40 to $80 \mathrm{~Hz}$ is caused by the onset of output by the Pacinian mechanoreceptor system. It is unlikely that such a sharp change in human vibration perception sensitivity can be due to mechanical factors related to the coupling between the vibrating structure and the human.

In order to consider the differences that might arise in practice when using $\mathrm{W}_{\mathrm{h}}$, or $\mathrm{W}_{\mathrm{s}}$ or the inverse of the data synthesis curve to weight a hand-arm vibration exposure, Figure 5 compares the three possibilities. Important differences can be noted at all frequencies below approximately $160 \mathrm{~Hz}$ with particularly large differences occurring between $\mathrm{W}_{\mathrm{h}}$ and the other two representations for frequencies lower than $6.3 \mathrm{~Hz}$. The differences between the possible weightings would be expected to effect the evaluation of automotive tyres, suspension systems and steering systems.

\section{[Insert Figure 5 Here]}




\section{Conclusions}

Psychophysical tests of human perception of steering wheel rotational vibration were performed using a laboratory test rig which simulated an automotive driving posture. Four equal sensation and one annoyance threshold test were performed for each of 15 subjects who held the steering wheel with both hands using a grip strength that they considered indicative of driving on a country road. All four equal sensation curves showed a general tendency of reduced skin sensitivity with increasing frequency. Changes in the slope of the equal sensation curves occurring at two transition points, one at 6.3 and the other at $50 \mathrm{~Hz}$. The data was summarised by means of linear regression in the intervals from 3 to $6.3 \mathrm{~Hz}$ and from 6.3 to $50 \mathrm{~Hz}$, while a quadratic expression was required above $50 \mathrm{~Hz}$.

Inversion and normalization of the regression curves provided a basis from which to define a frequency weighting for evaluating human perception of steering vibration. The proposed $\mathrm{W}_{\mathrm{s}}$ weighting has a slope of $0 \mathrm{~dB}$ per octave from 3 to $6.3 \mathrm{~Hz},-6 \mathrm{~dB}$ per octave from 6.3 to $50 \mathrm{~Hz}, 0 \mathrm{~dB}$ per octave from 50 to $160 \mathrm{~Hz}$ and -10 dB per octave from 160 to $315 \mathrm{~Hz}$. Comparison of $\mathrm{W}_{\mathrm{s}}$ to the well-known $\mathrm{W}_{\mathrm{h}}$ frequency weighting of ISO 5349-1 and BS 6842 and to a weighting based on equal sensation data from translating plates and handles found in the literature suggests important differences between the three representations at all frequencies below approximately $160 \mathrm{~Hz}$. A particular point of note is the lower human sensitivity to vibration indicated by $\mathrm{W}_{\mathrm{h}}$ at frequencies lower than $6.3 \mathrm{~Hz}$. In light of the differences between the possible weightings the choice of one or the other would be expected to effect the evaluation of automotive tyres, suspension systems and steering systems.

\section{References}

Baddeley, A., 1997. Human Memory: theory and practice. Psychology Press Ltd., Hove, East Sussex.

Bolanowski, S.J., Gescheider, G.A., Verillo, R.T., Checkosky, C.M., 1988. Four channels mediate the 
mechanical aspects of touch. Journal of the Acoustical Society of America 84, 1680-1694.

British Standard BS 7085, 1989. Safety aspects of experiments in which people are exposed to mechanical vibration and shock. British Standards Institution, London.

British Standard BS 6842, 1987. Measurement and evaluation of human exposure to vibration transmitted to the hand. British Standards Institution, London.

Buström, L., Lundström, R., 1994. Absorption of vibration energy in the hand and arm. Ergonomics 37 (5), 879-890.

Entran Devices Inc., 1991. MSC Series Multi-Channel Conditioning Unit Instruction Manual. Entran Devices Inc, Fairfield, New Jersey.

Gearing and Watson Electronics Ltd., 1995. GW Vibration Test System Manual. Gearing and Watson electronics Ltd., Hailsham, East Sussex

Gescheider, A.G., 1997. Psychophysics: The Fundamentals, 3rd Edition, Lawrence Erlbaum Associates Publishers, Mahwah, New Jersey.

Giacomin, J. and Abrahams, O., 2000. Human fatigue due to automobile steering wheel vibration. SIA Conference on Car and Train Comfort, Le Mans, France, $15^{\text {th }}$ to $16^{\text {th }}$ November.

Griffin, M.J., 1997. Measurement, evaluation, and assessment of occupational exposure to handtransmitted vibration. Journal of Occupational and Environmental Medicine 54 (2), 73-89.

Harada, N., 1978. Studies on the changes in the vibratory sensation threshold at the finger tip in relation to some physical parameters of exposed vibration. Part 2: A study on the equal TTS curves of the vibratory sensation and the hygienic allowable limit of portable mechanized tool. Japanese Journal of Hygiene 5, 706-717.

Hinton, P.R., 1998. Statistics Explained: a guide for social science students. Routledge, New York. Human Dynamics Group, 2000. Michelin Proving Grounds Test Database. Department of Mechanical Engineering, The University of Sheffield.

International Standard ISO 13091-1, 2001. Mechanical Vibration - Vibrotactile perception thresholds 
for the assessment of nerve dysfunction, Part 1: Methods of measurement at the fingertips, International Organization for Standardization, Geneva.

International Standard ISO 5349-1, 2001. Mechanical Vibration - Measurement and assessment of human exposure to hand-transmitted vibration - Part 1: General guidelines. International Organization for Standardization, Geneva.

Isomura, A., Hara, T., Kmiya, K., 1995. Human factors on driver's steering wheel operation: three parameters evaluating characteristics of driver's steering wheel operations. JSAE Review 16, 388-410.

Laming, D., 1984. The relativity of "absolute" judgments. British Journal of Mathematical and Statistical Psychology 37, 152-183.

Mansfield, N.J., Marshall, J.M., 2001. Symptoms of musculoskeletal disorders in stage rally drivers and co-drivers. British Journal of Sports Medicine 35, 314-320.

Masmejean, E.H., Chavane, H., Chantegret, A., Issermann, J.J., Alnot, J.Y., 1999. The wrist of the formula one driver. British Journal of Sports Medicine 33, 270-273.

Miwa, T., 1967. Evaluation methods for vibration effect, Part3: Measurements of threshold and equal sensation contours on hand for vertical and horizontal sinusoidal vibrations. Industrial Health 5, 213220.

Morioka, M., 1999. Effect of contact location on vibration perception threshold in the glabrous skin of the human hand. $34^{\text {th }}$ United Kingdom Group Meeting on Human Responses to Vibration, Ford Motor Company, Dunton, Essex, England, $22^{\text {nd }}$ to $24^{\text {th }}$ September.

Nishiyama, K., Watanabe, S., 1981. Temporary threshold shift of vibratory sensation after clasping a vibrating handle. International Archive of Occupational Environmental Health 49, 21-33.

Norkin, C.C., White, D.J., 1995. Measurement of Joint Motion, $2^{\text {nd }}$ Edition. F.A Davis Company, Philadelphia.

Pak, C.H., Lee, U.S., Hong, S.C., Song, S.K., Kim, J.H., Kim, K.S., 1991. A study on the tangential vibration of the steering wheel of passenger car. Society of Automotive Engineers paper 912565.

Peruzzetto, P., 1988. Assessing the relative importance of hand vibration with respect to whole-body 
vibration. The United Kingdom and French Joint Meeting on Human Responses to Vibration, I.N.R.S., Vandoeuvre, France, 26 to $28^{\text {th }}$ September.

Pottinger, M.G., Marshall, K.D., Lawther, J.M., Thrasher, D.B., 1986. A review of tire/pavement interaction induced noise and vibration. In Pottinger, M.G. and Yager, T.J. (Editors), ASTM STP929 The Tire Pavement Interface. ASTM, Philadelphia, 183-287.

Reynolds, D.D., Keith, R.H., 1977. Hand-arm vibration, Part 1: Analytical model of the vibration response characteristics of the hand. Journal of Sound and Vibration 51 (2), 237-253.

Reynolds, D.D., Angevine, E.N., 1977. Hand-arm vibration, Part 2: Vibration transmission characteristics of the hand and arm. Journal of Sound and Vibration 51 (2), 255-265.

Reynolds, D.D., Standlee, K.G., Angevine, E.N., 1977. Hand-arm vibration, Part 3: Subjective responses characteristics of individuals to hand induced vibration. Journal of Sound of Vibration 51 (2), 255-265.

Reynolds, D.D., Soedel, W., 1972. Dynamic Response of hand-arm system to sinusoidal input. Journal of Sound and Vibration 21 (3), 339-352.

Shayaa, M.S., Giacomin, J., Dormegnie, E., Richard, L., 2001. Human perception of sinusoidal steering wheel rotational vibration. $36^{\text {th }}$ UK Group Conference on Human Responses To Vibration, Centre for Human Sciences, Farnborough, UK, $12^{\text {th }}$ to $14^{\text {th }}$ September.

Thurlby Thandar Instruments Ltd., 1994. TG 1010 Programmable 10 MHz DDS Function Generator, User Manual. Thurlby Thandar Instruments, Huntingdon, Cambridgeshire.

Verillo, R.T., 1985. Psychophysics of vibrotactile stimulation. Journal of the Acoustical Society of America 77, 225-232.

Verillo, R.T., 1966. A duplex mechanism of mechanoreception. Proceedings of the First International Symposium on the Skin Senses, Florida, 139-159. 


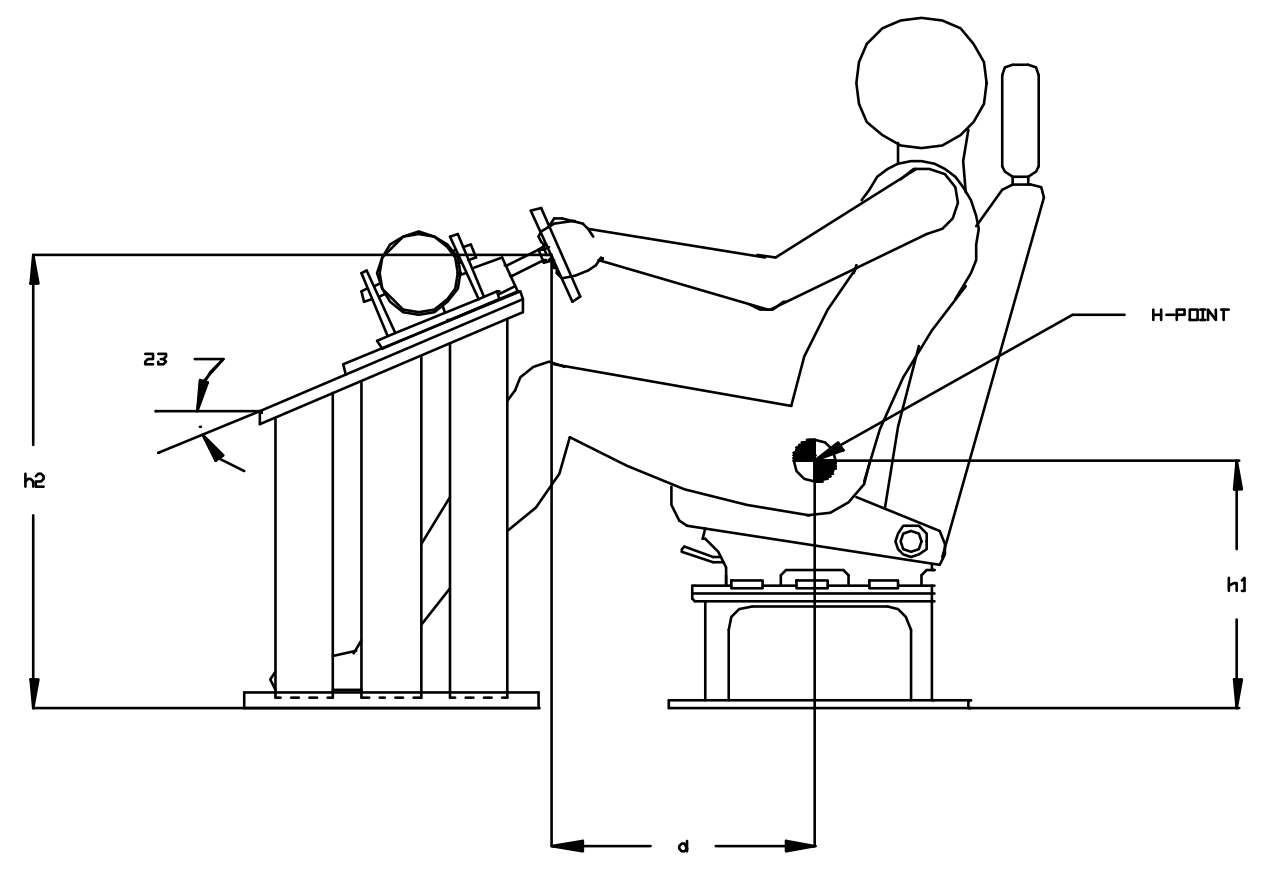

Figure 1) Steering wheel rotational vibration test rig. 


\begin{tabular}{|c|c|}
\hline Geometric Parameter & Value \\
\hline Steering column angle with respect to floor & $23^{\circ}$ \\
\hline Steering wheel hub centre height above floor (h2) & $710 \mathrm{~mm}$ \\
\hline Seat H point height from floor (h1) & $275 \mathrm{~mm}$ \\
\hline Horizontal distance adjustable from H point to steering wheel hub centre (d) & $390-550 \mathrm{~mm}$ \\
\hline Steering wheel tube diameter & $12.5 \mathrm{~mm}$ \\
\hline Steering wheel diameter & $325 \mathrm{~mm}$ \\
\hline
\end{tabular}

Table 1) Geometric dimensions of the steering wheel rotational vibration test rig.

\begin{tabular}{|c|c|c|c|c|c|}
\hline \multirow[b]{2}{*}{ Test No. } & \multicolumn{4}{|c|}{ Equal Sensation Test Variables } & \multirow[b]{2}{*}{$\begin{array}{c}\text { Factors } \\
\text { Investigated }\end{array}$} \\
\hline & $\begin{array}{c}\text { Reference } \\
\text { Frequency } \\
\text { (Hz) }\end{array}$ & $\begin{array}{l}\text { Reference } \\
\text { Amplitude } \\
\text { (m/s }{ }^{2} \text { r.m.s) }\end{array}$ & $\begin{array}{c}\text { Short } \\
\text { Break* } \\
\text { (seconds) } \\
\end{array}$ & $\begin{array}{c}\text { Type of } \\
\text { Reference } \\
\text { Signal } \\
\end{array}$ & \\
\hline 1 & 63 & 1.0 & 30 & Fixed & \multirow[t]{2}{*}{ Amplitude } \\
\hline 2 & 63 & 1.5 & 30 & Fixed & \\
\hline 1 & 63 & 1.0 & 30 & Fixed & \multirow[t]{2}{*}{$\mathrm{TTS}_{\mathrm{v}}$} \\
\hline 3 & 63 & 1.0 & No break & Fixed & \\
\hline 3 & 63 & 1.0 & No break & Fixed & \multirow{2}{*}{$\begin{array}{c}\text { Psychophysica } \\
\text { Method }\end{array}$} \\
\hline 4 & 63 & 1.0 & No break & Moving $^{\Psi}$ & \\
\hline
\end{tabular}

Table 2) Four equal sensation tests were used in pairs to observe the effects of reference stimuli amplitude, temporary threshold shift and psychophysical procedure. * Break given to the subjects after each pair of reference and test stimuli. ${ }^{\Psi}$ A variation of method of adjustment was used. 

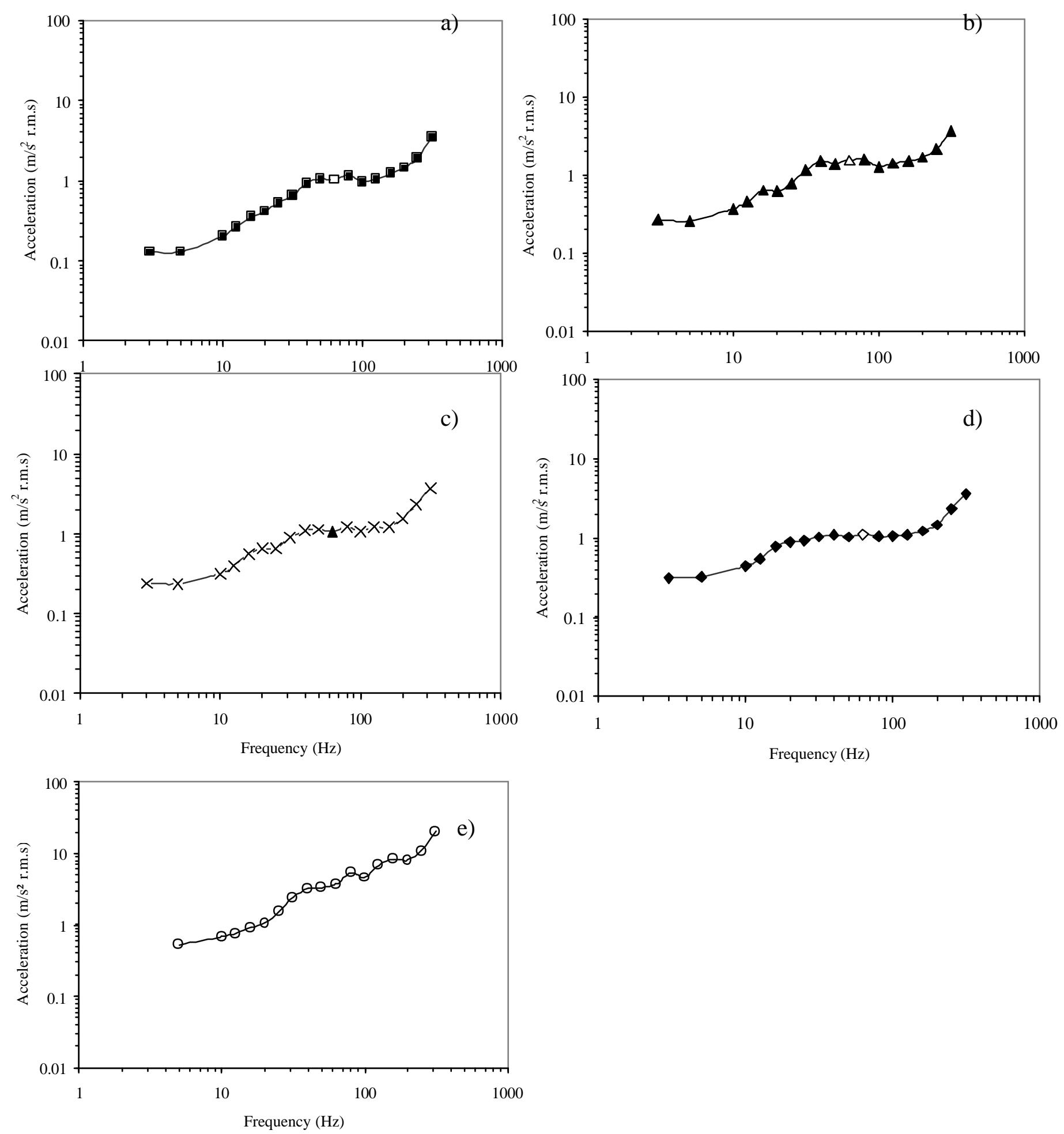

Figure 2) Mean equal sensation curves ( $\mathrm{n}=15$ subjects) a) Test 1 : reference signal $63 \mathrm{~Hz}$ at 1.0 $\mathrm{m} / \mathrm{s}^{2}, 30 \mathrm{~s}$ break. b) Test $2:$ reference signal $63 \mathrm{~Hz}$ at $1.5 \mathrm{~m} / \mathrm{s}^{2}$ r.m.s, 30 s break. c) Test 3 : reference signal $63 \mathrm{~Hz}$ at $1.0 \mathrm{~m} / \mathrm{s}^{2}$ r.m.s, no break. d) Test 4 : reference signal $63 \mathrm{~Hz}$ at $1.0 \mathrm{~m} / \mathrm{s}^{2}$ r.m.s, no break, moving reference. e) Annoyance Threshold Test 


\begin{tabular}{|c|c|c|c|c|}
\hline & Test 1 & Test 2 & Test 3 & Test 4 \\
\hline Frequency (Hz) & Mean \pm SD & Mean \pm SD & Mean \pm SD & Mean \pm SD \\
\hline 3 & $0.13 \pm 0.03$ & $0.27 \pm 0.02$ & $0.24 \pm 0.06$ & $0.31 \pm 0.14$ \\
\hline 5 & $0.13 \pm 0.04$ & $0.26 \pm 0.07$ & $0.24 \pm 0.07$ & $0.32 \pm 0.15$ \\
\hline 10 & $0.20 \pm 0.06$ & $0.37 \pm 0.10$ & $0.31 \pm 0.07$ & $0.44 \pm 0.21$ \\
\hline 12.5 & $0.27 \pm 0.08$ & $0.46 \pm 0.12$ & $0.40 \pm 0.08$ & $0.55 \pm 0.21$ \\
\hline 16 & $0.35 \pm 0.10$ & $0.64 \pm 0.27$ & $0.56 \pm 0.15$ & $0.78 \pm 0.35$ \\
\hline 20 & $0.41 \pm 0.09$ & $0.62 \pm 0.16$ & $0.65 \pm 0.14$ & $0.89 \pm 0.39$ \\
\hline 25 & $0.52 \pm 0.14$ & $0.78 \pm 0.25$ & $0.65 \pm 0.21$ & $0.93 \pm 0.39$ \\
\hline 31.5 & $0.65 \pm 0.21$ & $1.15 \pm 0.24$ & $0.89 \pm 0.18$ & $1.03 \pm 0.35$ \\
\hline 40 & $0.93 \pm 0.24$ & $1.50 \pm 0.36$ & $1.09 \pm 0.21$ & $1.08 \pm 0.18$ \\
\hline 50 & $1.05 \pm 0.22$ & $1.40 \pm 0.24$ & $1.14 \pm 0.25$ & $1.02 \pm 0.23$ \\
\hline 63 & $1.03 \pm 0.00$ & $1.56 \pm 0.00$ & $1.06 \pm 0.02$ & $1.10 \pm 0.05$ \\
\hline 80 & $1.16 \pm 0.23$ & $1.57 \pm 0.37$ & $1.22 \pm 0.28$ & $1.05 \pm 0.13$ \\
\hline 100 & $0.97 \pm 0.21$ & $1.29 \pm 0.30$ & $1.06 \pm 0.26$ & $1.06 \pm 0.26$ \\
\hline 125 & $1.04 \pm 0.58$ & $1.42 \pm 0.61$ & $1.22 \pm 0.32$ & $1.10 \pm 0.32$ \\
\hline 160 & $1.25 \pm 0.53$ & $1.52 \pm 0.29$ & $1.21 \pm 0.35$ & $1.23 \pm 0.37$ \\
\hline 200 & $1.45 \pm 1.17$ & $1.68 \pm 0.74$ & $1.56 \pm 0.38$ & $1.44 \pm 0.50$ \\
\hline 250 & $1.91 \pm 1.35$ & $2.18 \pm 0.62$ & $2.32 \pm 0.97$ & $2.32 \pm 0.90$ \\
\hline 315 & $3.56 \pm 2.30$ & $3.73 \pm 1.60$ & $3.70 \pm 1.35$ & $3.60 \pm 1.80$ \\
\hline
\end{tabular}

Table 3) Mean and standard deviation values of the equal sensation test results for 15 subjects in units of r.m.s. $\mathrm{m} / \mathrm{s}^{2} .{ }^{\perp}$ Denotes the reference frequency at $63 \mathrm{~Hz}$.

\begin{tabular}{|c|c|c|c|}
\hline Segment & $\begin{array}{c}\text { Frequency } \\
\text { Range (Hz) }\end{array}$ & $\begin{array}{c}\text { Regression } \\
\text { Equation }\end{array}$ & $\begin{array}{c}\text { Coefficient of } \\
\text { determination, } \mathbf{R}^{\mathbf{2}}\end{array}$ \\
\hline 1 & $3.0-6.3$ & $s=0.00004 f+0.1299$ & 0.85 \\
\hline 2 & $6.3-50$ & $s=0.0215 f+0.001$ & 0.99 \\
\hline 3 & $50-315 \mathrm{~Hz}$ & $s=0.00006 f^{2}-0.0112 f+1.5$ & 0.97 \\
\hline
\end{tabular}

Table 4) Regression equations fitted to the data of equal sensation test 1 and test 2 in three segments. 

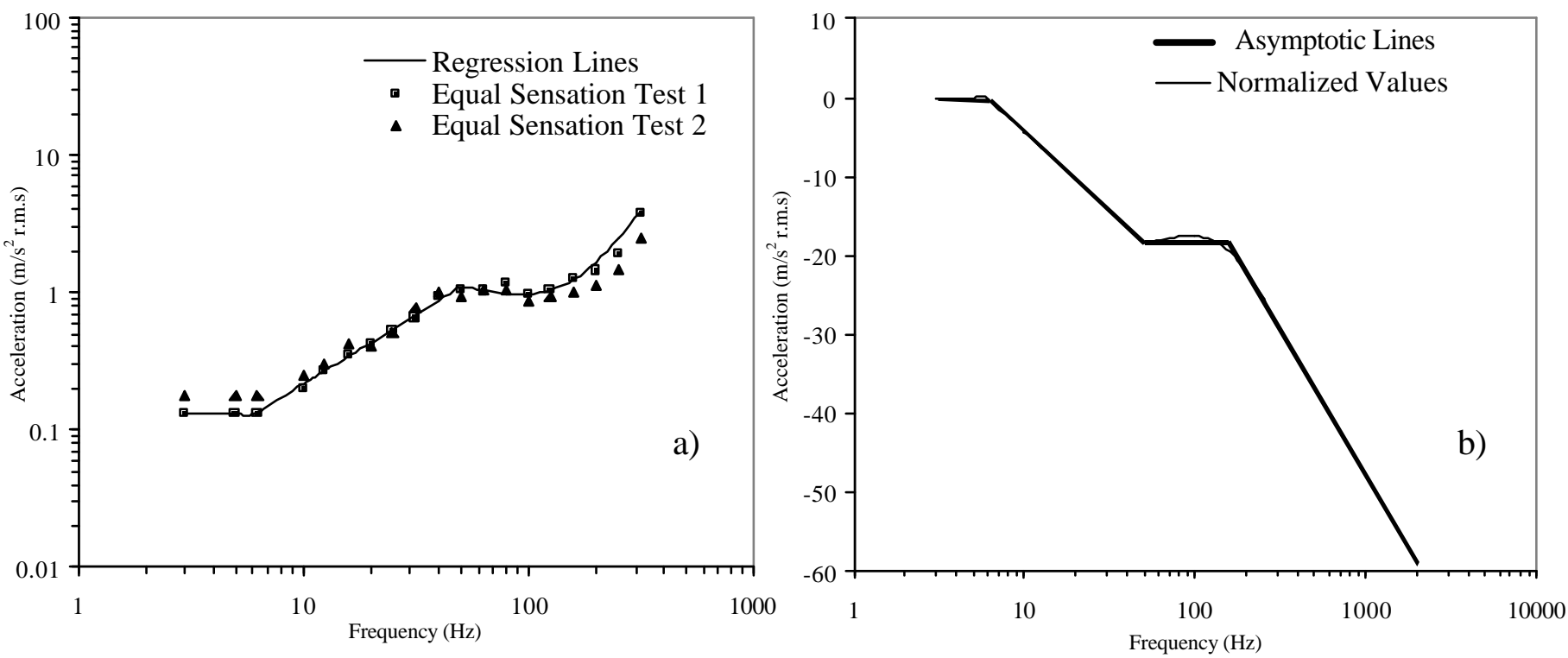

Figure 3) Definition of the $\mathrm{W}_{\mathrm{s}}$ frequency weighting for steering wheel rotational vibration.

(a) regression curves fitted to the data of equal sensation test 1 and test 2

(b) asymptotic approximation lines taken to simplify the weighting shape

\begin{tabular}{|c|c|c|c|}
\hline Segment & $\begin{array}{c}\text { Frequency } \\
\text { Range (Hz) }\end{array}$ & $\begin{array}{c}\text { Regression } \\
\text { Equation }\end{array}$ & $\begin{array}{c}\text { Coefficient of } \\
\text { determination, } \mathbf{R}^{\mathbf{2}}\end{array}$ \\
\hline 1 & $1.0-6.3$ & $s=0.0087 f+0.09$ & 0.70 \\
\hline 2 & $6.3-80$ & $s=0.012 f+0.0668$ & 0.87 \\
\hline 3 & $80-1000$ & $s=0.00008 f^{2}+0.0187 f+2.1$ & 0.99 \\
\hline
\end{tabular}

Table 5) Regression equations fitted to the equal sensation synthesis curve in three segments. 

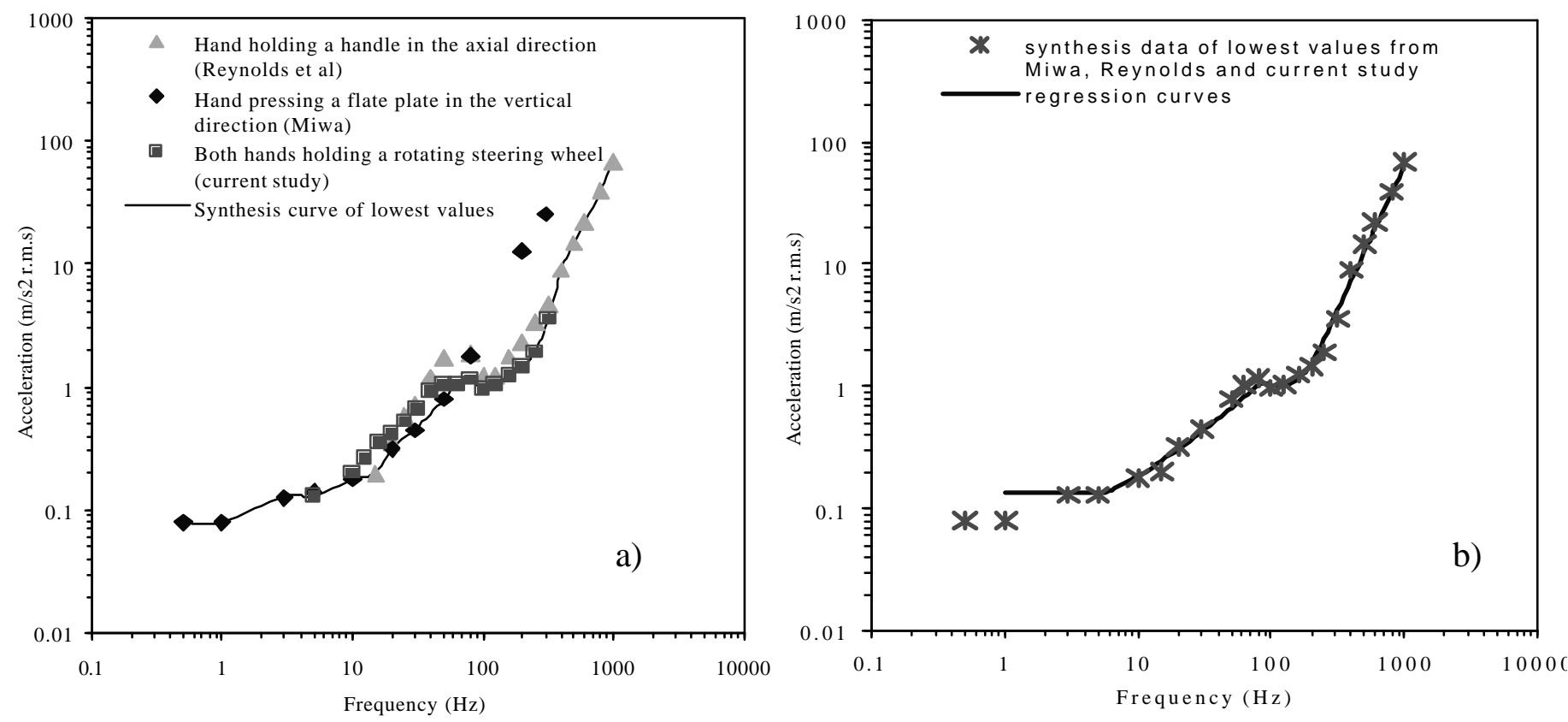

Figure 4) Synthesis curve of hand-arm system vibration perception.

a) Equal sensation data from studies of translational or rotational vibration.

b) Regression curves fitted over 3 segments; 1 to $6.3 \mathrm{~Hz}, 6.3$ to $80 \mathrm{~Hz}$, and 80 to $1000 \mathrm{~Hz}$.

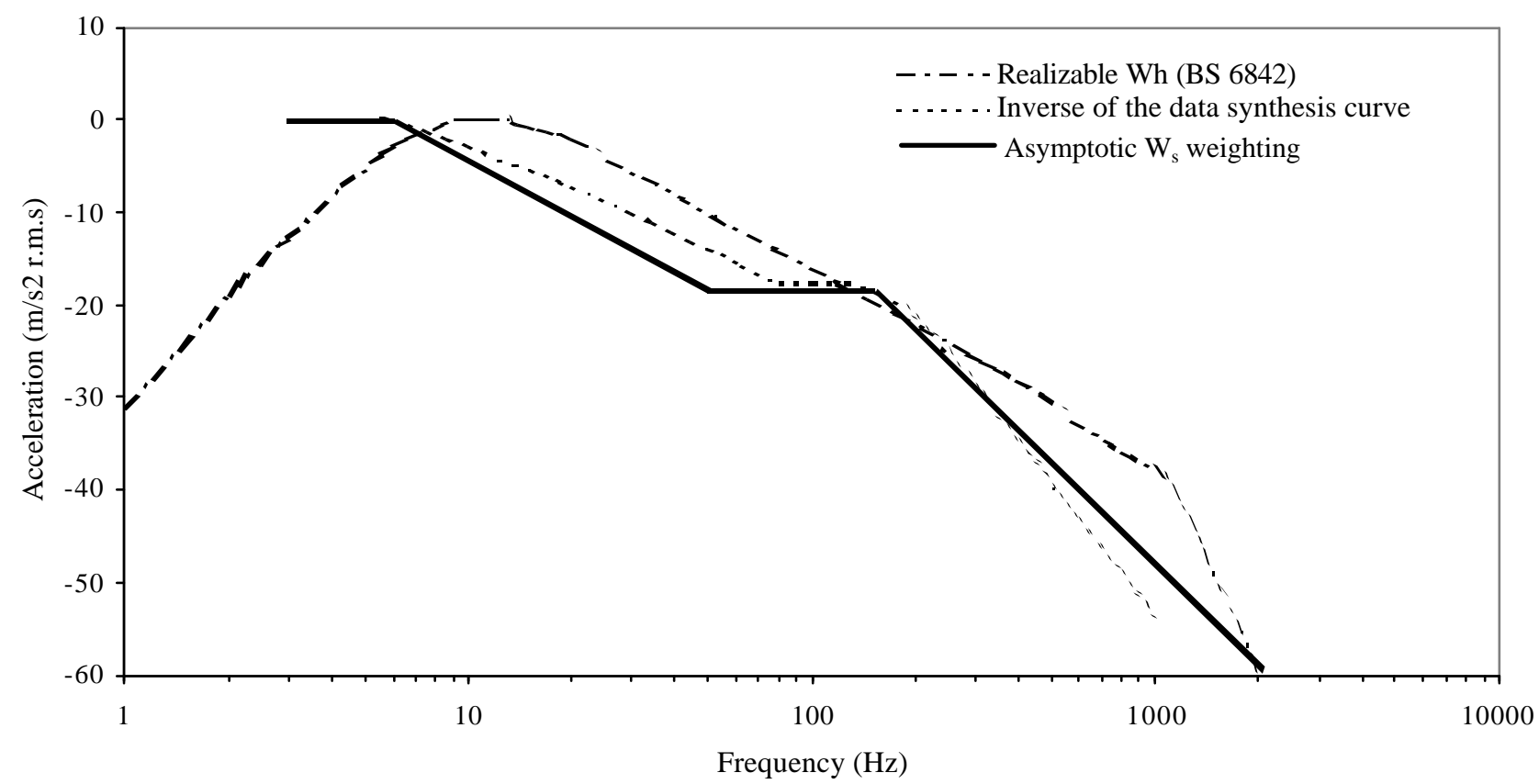

Figure 5) Comparison between the proposed $\mathrm{W}_{\mathrm{s}}$ frequency weighting for steering wheel rotational vibration, a weighting based on the equal sensation data synthesis curve for hand-arm vibration, and frequency weighting $\mathrm{W}_{\mathrm{h}}$ from ISO5349-1 and BS6842. 